\title{
NÃO SOU DEFICIENTE: SOU UMA PESSOA COM DEFICIÊNCIA. UMA ONTOLOGIA DOS DIREITOS
}

\author{
I AM NOT HANDICAPPED: I AM A PERSONS WITH DISABILITY. AN \\ ONTOLOGY OF RIGHTS
}

\author{
Hugo Daniel da Cunha Lança Silva \\ Doutor em Direito, desde 2015, pela Faculdade de Direito da Universidade do Porto. \\ E-mail: hdlanca@gmail.com \\ Bruno Domingos \\ Licenciado em Solicitadoria - IPBeja \\ E-mail: bruno_f_domingos@hotmail.com
}

CONVIDADOS

RESUMO: Como Michel Foucault enfatizou, existe, desde tempos imemoriais. uma tendência para esconder tudo o que se afasta do estranho paradigma da normalidade. Tendo por base esta triste premissa, não podemos estranhar que a deficiência tenha sido escamoteada numa sociedade que historicamente tem dificuldades em lidar com a diferença. Assim, este texto tem dois singelos objetivos: retirar a problemática das pessoas com deficiência da obscuridade que continuam subjugadas e elencar alguns dos direitos que lhe são consagrados na legislação, trazendo luz a um tema rodeado de sombras.

Palavra-Chave: Discriminação. Proteção dos Direitos. Pessoas com Deficiência.

SUMMARY: As Michel Foucault emphasized, since immemorial time, our society has a tendency to hide everything that moves away from the strange paradigm of normality. On the basis of this sad premise, is not surprising that disability has been concealed in a society that historically has difficulty dealing with difference. Therefore, the aim of this text is to pursue two simple objectives: to remove the problematic of persons with disabilities from the obscurity that remain subdued and to list some of the rights that are provided by law, bringing light to a theme surrounded by shadows. Key Word: Discrimination. Protection of Rights. Persons with Disabilities.

\section{INTRODUÇÃO}

Este artigo tem como desiderato facilitar a compreensão do conceito de deficiência e [tentar] decifrar a criptográfica legislação que esmaga aqueles que quotidianamente lidam de perto (ou se importam) com algum tipo de deficiência. 
Assumida a premissa, partimos para este texto com os pés bem assentes na realidade, pelo que, não ignoramos, a norma social ainda está intrincada em preconceitos e a pessoa com deficiência continua na vox populi [bem como, infelizmente, na prática dos burocratas do direito] a ser um deficiente. Porque, amiúde, a ignorância faz parte do nosso património cultural, a sociedade continua a interpretar as pessoas com deficiência como inábeis para cuidar de si e dos seus interesses, eternas carentes da proteção [piedade] de terceiros, limitadas na sua capacidade para querer e entender, credoras de uma omnipresença que as ajude nas suas múltiplas imperfeições, entendendo-a como inapta para fazer ouvir a sua própria voz. E, porque o paternalismo, ainda que bem-intencionado, é a primeira das sevícias, pais, cuidadores e instituições reiteradamente conseguem ver para lá da deficiência e interpretar a pessoa com deficiência como uma pessoa, com todo o peso moral e jurídico que lhe é intrínseco.

Dessarte, antes do homem, a sociedade vê a cadeira; previamente ao olhar para um invisual, lhe reconhecemos a bengala; aumentamos o tom de voz, se tentamos conversar com um surdo, munidos da mesma candura ingénua com que abrimos mais a voz para falar em português com um falante da língua inglesa; fixamos o rosto de quem tem síndrome de down sem atender à idiossincrasia do petiz. Cientes que esta é a triste verdade, esclarecemos, escrevemos estas linhas a ouvir BEETHOVEN, privilégio que, devido à surdez, o compositor não teve no final da sua vida, sem que tal o tenha impedido de oferecer à eternidade algumas das mais belas obras que a nossa civilização alguma vez ouviu ou ouvirá; como poderiam ser escritas ao som de Andrea BOCELLI. Encanta-nos a pintura, e poucas telas são mais belas do que a noite estrelada, pintada pela pena de um louco genial que se tornou imortal com o nome de Van GOGH; como, reiteradamente, contemplamos a obra de Frida KAHLO, que, não obstante a considerável coleção de doenças, nunca perdeu o seu brilhantismo único. Amiúde rodeamo-nos de pessoas de alto coturno (real ou inflacionado), mas nunca privamos com uma mente tão brilhante como HAWKING, cuja dimensão intelectual é única no nosso tempo. John NASH será dos poucos que se lhe poderá comparar, porque o seu brilhantismo nunca cedeu perante a paranoia. Ou convocar o disléxico Charles DARWIN, que mudou a forma como pensamos o mundo. Se tivermos por paradigma a literatura, que é um fogo que arde sem se ver, sendo que a incapacidade de escrever como gostaríamos é uma é ferida que dói, e se sente, é um contentamento descontente, é dor que desatina sem doer, como nos ensinou aquele rapaz cego que salvou o seu livro a nado com uma pala no olho. Como, o que teria sido da Europa saída da carnificina da Segunda Grande Guerra, se Franklin ROOSEVELT, sentado na sua cadeira de rodas, não tivesse compreendido que aquela guerra nascera da sede de vingança de 1918 e da condenação à fome dos derrotados, tendo criado a arquitetura que permitiu o surgimento do Plano Marshall (hoje olimpicamente ignorado por aqueles que mais dele beneficiaram).

Serve o prelúdio uma necessidade desnecessária: recordar que a deficiência não define uma pessoa e que, quer personagens míticas do nosso espaço cultural quer milhares e milhares de cidadãos anónimos, em heterogéneas áreas, tiveram a sapiência, a sagacidade, tantas vezes a resiliência, para quotidianamente nos recordar, que, na esmagadora maioria dos casos, as limitações não são pessoais, mas resultam de uma arquitetura social inapta para lidar com a diferença.

Porque, uma pessoa com deficiência ou incapacidade não pode continuar a ser sinónimo de "cidadão de segunda" e, tal como os restantes cidadãos, também são sujeitos de direitos e de obrigações. Só a ignorância e a educação (ou falta dela) permite esta discriminação, sendo, por isso, crucial gritar os direitos das pessoas com deficiência de modo a instruir toda uma sociedade, esta sim deficiente, enquanto não olhar para todas as pessoas da mesma forma e saber aproveitar 
as qualidades e virtudes que cada um lhe pode oferecer. Contudo, infelizmente, o que ainda verificamos é uma conexão entre deficiência e discriminação, pobreza e exclusão social ${ }^{1}$, fazendo com que as pessoas com deficiência continuem a figurar entre os mais desfavorecidos dos desfavorecidos socialmente ${ }^{2}$.

Quando cogitamos as raízes, o fator comum a esta exclusão prende-se com as barreiras enraizadas na nossa sociedade, sejam estas arquitetónicas, comunicacionais, económicas ou culturais que obstam a inclusão da pessoa com deficiência e a sua interação com a pólis. Bem como, as barreiras mentais de uma sociedade que vê a deficiência como uma tragédia que exige ser escondida. E, se seria injusto não realçar um progresso e que ninguém poderia razoavelmente acreditar que a necessária mudança de mentalidades fosse tão célere como o surgimento de uma estrela [(de)cadente] de música pop ou de um ícone de um reality show, sendo insofismável uma evolução nos últimos anos, persiste um longo [longuíssimo] caminho a trilhar.

\section{NO COTEJO DA DEFINIÇÃO DO CONCEITO}

Escrito o introito, entramos no cerne deste estudo, construindo com base na premissa de que se a sociedade não pula e avança pelas mãos de um decreto-lei, pelo que, como ensinou Rudolf von IHERING, se a finalidade do direito é a paz, a luta é o meio de consegui-la, enquanto o Direito tiver de afastar o ataque causado pela injustiça. Destarte, o Direito pode ser um fator fundamental para induzir uma mudança de mentalidades e comportamentos, porquanto se é verdade que faz parte da sociedade e dos cidadãos "vigiarem" os preconceitos, ações e atitudes discriminatórias, a Lei pode proibi-las, exigindo-se uma legislação que defenda os direitos das pessoas com deficiência, que garanta a igualdade, a inclusão, e a sua autodeterminação, bem como eliminar barreiras, sejam elas arquitetónicas, comunicacionais, sociais, culturais, económicas, seja através da sensibilização e bom senso, seja através da imperatividade da norma jurídica ${ }^{3}$.

Um tom de otimismo: nunca as temáticas da deficiência tiveram tanto protagonismo nas agendas mediáticas (e, consequentemente, nas agendas dos governantes). Seja para debater o próprio conceito, seja para questionar as medidas de inclusão, políticas sociais, educação, discriminação, alterações ambientais, inter alia, temáticas que, mais do que discutir, urge implementar. Porque de estudos e debates está o inferno cheio...

Mas, de regresso à nossa rota, importa começar pelo início e in casu exige-se densificar o conceito de deficiência.

\footnotetext{
${ }^{1} \mathrm{O}$ Banco Mundial estima que $20 \%$ das pessoas mais pobres tenham uma deficiência e, em geral, são consideradas como as mais desfavorecidas pelos membros da sua própria comunidade. Cerca de 386 milhões de pessoas em idade ativa têm, pelo menos uma, deficiência, segundo a Organização Mundial do Trabalho (OIT). No seu caso, o desemprego atinge os $80 \%$, em alguns países. Os empregadores partem, com frequência, do princípio de que as pessoas com deficiência não são capazes para trabalhar (UNRIC).

${ }^{2}$ Segundo a UNICEF, 30\% dos jovens que vivem na rua têm deficiência. Nos países em desenvolvimento, 90\% das crianças com deficiência não frequentam a escola, segundo a UNESCO (UNRIC).

${ }^{3}$ Estudos comparativos das leis sobre pessoas com deficiência mostram que apenas $45 \%$ dos países têm uma legislação anti discriminatória ou que faça referência específica às pessoas com deficiência (UNRIC). A principal fonte dos direitos das pessoas com deficiência que vigora no sistema jurídico português provém do regime jurídico dos ordenamentos jurídicos europeus.
} 
Dessarte, inexiste uma definição de deficiência apta para captar toda a diversidade de entendimentos e conceitos em constante evolução ${ }^{4}$. Aprioristicamente, tomemos por paradigma o conceito simples e objetivo oferecido pela Lei n. ${ }^{\circ} 38 / 2004$, de 18 de agosto, que no seu artigo $2 .^{\circ}$ considera

aquela que, por motivo de perda ou anomalia, congénita ou adquirida, de funções ou de estruturas do corpo, incluindo as funções psicológicas, apresente dificuldades específicas suscetíveis de, em conjugação com os fatores do meio, lhe limitar ou dificultar a atividade e a participação em condições de igualdade com as demais pessoas.

A definição oferecida é semelhante ao plasmado na Convenção sobre os Direitos das Pessoas com Deficiência que, no seu artigo $1 .^{\circ}$, define pessoas com deficiência como

aquelas que têm incapacidades duradouras físicas, mentais, intelectuais ou sensoriais, que em interação com várias barreiras podem impedir a sua plena e efetiva participação na sociedade em condições de igualdade com os outros.

Como se infere da ampla definição cotejada pela ONU, que agrupa pessoas com uma quantidade de patologias bastante diferenciadas, este não constitui um grupo homogéneo. Com efeito, inclui pessoas com deficiências mentais, visuais, auditivas ou da fala, as que têm mobilidade reduzida e ainda as chamadas deficiências orgânicas. No entanto, não obstante a sua diversidade, é mais aquilo que as une do que aquilo que as separa e, todas elas, devido às características das suas limitações, ainda que de diferentes maneiras, enfrentam inúmeras barreiras que devem ser "desconstruídas" e superadas 5 .

Para oferecer uma dimensão quantitativa da questão, sublinhe-se que cerca de $10 \%$ da população mundial ${ }^{6}$, ou seja, mais de 700 milhões de pessoas têm algum tipo de deficiência, sendo que, cerca de 200 milhões têm dificuldades funcionais significativas ${ }^{7}$, constituindo esta categoria a maior minoria do mundo. Refira-se que a este número já significativo, podemos aglutinar as

\footnotetext{
${ }^{4}$ Como resulta da Convenção sobre os Direitos da Pessoa com Deficiência que sublinha que este é um conceito em evolução e que a deficiência resulta da interacção entre pessoas com incapacidades e barreiras comportamentais e ambientais que impedem a sua participação plena e efectiva na sociedade em condições de igualdade com as outras pessoas.

${ }^{5}$ Por seu turno, a Organização Mundial de Saúde (OMS) é outro dos organismos que tem procurado continuamente cotejar uma definição geral da deficiência. Nesse sentido, desde 1980, a Classificação Internacional de Deficiências, Incapacidades e Desvantagens (ICIDH) tem sido o mais importante sistema de classificação no processo de compreender e definir a deficiência, tendo esta sido revista no final dos anos 90, dando origem, em 2002, à Classificação Internacional de Funcionalidade, Incapacidade e Saúde (CIF). Ensina-nos a OMS que a CIF é uma classificação com múltiplas finalidades, suscetível de ser utilizada de forma transversal em diferentes áreas disciplinares e setores, entre os quais saúde, educação, segurança social, emprego, economia, política social, alterações ambientais, desenvolvimento de políticas e de legislação em geral. Foi, por isso, aceite pelas Nações Unidas como uma das suas classificações sociais, considerando-a o quadro de referência apropriado para a definição da legislação internacional sobre os direitos humanos, bem como, da legislação nacional.

${ }^{6}$ No que diz respeito à realidade portuguesa, de acordo com os Censos de 2001, existiam 636.059 pessoas com deficiência, correspondendo a cerca de $6,5 \%$ da população portuguesa residente (INE, 2015).

${ }^{7}$ No concerne à circunstância geográfica, $80 \%$ das pessoas com deficiência vivem nos países em desenvolvimento, segundo o Programa das Nações Unidas para o Desenvolvimento (PNUD).
} 
pessoas com necessidades especiais de apoio ou acessibilidade, como, por exemplo, as grávidas ou parturientes ou o caso dos idosos, o que permite concluir que o universo das pessoas abrangidas por algum tipo de limitação tem uma dimensão significativa, transformando assim cada ser humano numa potencial pessoa com deficiência. Parafraseando uma célebre frase de RAE, todos os corpos são temporariamente “capazes”. Mais. Segundo a OMS, este número está a aumentar, devido ao crescimento demográfico, aos avanços da medicina e ao processo de envelhecimento ${ }^{8}$, prova provada da pertinência de meditar criticamente sobre a questão. Porque, é insofismável, constitui um problema central na sociedade.

\section{A DEFICIÊNCIA NA HISTÓRIA OU A HISTÓRIA DA DEFICIÊNCIA}

"Ao longo dos séculos a deficiência tem sido demonizada, reduzida às falhas do corpo e encarada como uma tragédia individual" (FONTES, Fernando 2016), que motivou práticas tão vis como o infanticídio de crianças com deformações físicas na Antiguidade Clássica ou o programa Aktion T4 que, na Alemanha nazi, exterminou milhares de cidadãos considerados incuravelmente doentes. Dessarte, quando mergulhamos na História subjazem quatro modelos, a saber, o modelo caritativo, o modelo médico, o modelo social e o modelo baseado em direitos.

O Modelo Caritativo interpreta as pessoas com deficiência como vítimas da sua incapacidade [tendo por barómetro a padronização da cultura e da sociedade ${ }^{9}$ ]. Consequentemente, a palavra pena é reiteradamente convocada para descrever o sentimento das "pessoas normais" em relação às pessoas com deficiência, numa visão recheada de aforismos, como, eles precisam da nossa ajuda, é preciso tomar conta delas é preciso caridade, sendo que, quase sempre, a institucionalização é entendida como a solução, porque a deficiência é compreendida como algo que invalida as pessoas "tornando-as" inaptas para uma vida independente.

Tendo por premissa que a inclusão pode ter custos financeiros elevados, tem sido prática comum (interpretada como lógica), ao longo das últimas cinco décadas, recorrer ao um modelo que condena as pessoas com deficiência a viver à margem da vida em sociedade, quer por via da institucionalização ${ }^{10}$ quer por via de uma reclusão domiciliária, promovida pelos familiares [ainda que investidos das melhores intenções], que, não obstante o aparente altruísmo generoso, assemelham-se a uma espécie de cativeiro. Com efeito, tendo por base estas premissas e preconceitos, as políticas a adotar perante o drama, a tragédia, o horror destas pessoas, limitamse a defender a necessidade de serviços especiais, instituições especiais, tratamento especial, porquanto estas pessoas são... especiais. Na nossa opinião, este modelo consegue ser ontologicamente tão eficiente que persuade as próprias pessoas com deficiência (e a quem com elas lida diariamente) de que não existe outra alternativa, levando-as a sentirem-se "inválidas" e a resignarem-se perante o insuportável peso da patologia.

\footnotetext{
${ }^{8}$ Nos países onde a esperança de vida é superior a 70 anos, cada indivíduo viverá com uma deficiência em média 8 anos, isto é $11,5 \%$ da sua existência (UNRIC).

${ }^{9}$ Como nos recordam, CARVAlHO, Suzy e FREITAS, Ana - Pessoa com Deficiência Intelectual ante a Lei 13.146/15. "Revista da AGU". Brasília-DF. v. 17, n. 1, p. 316.

${ }^{10}$ A institucionalização surge no início da revolução industrial com a criação de um grande número de asilos para pessoas com deficiência ( $c f m$. Barnes, Mercer e Shakespeare, 2000). Começam então a surgir os primeiros hospitais especializados como foi o caso do Hospital Général criado por Luis XIV em Paris em 1656, e do Hotel des Invalides, criado em 1674.
} 
Felizmente falamos de um modelo ultrapassado e cada vez menos aplicado, ainda que, infelizmente, com reminiscências nas mentes mais retrógradas e resilientes.

No que concerne ao Modelo Médico ${ }^{11}$, interpretam-se as pessoas com deficiência como pacientes com patologias físicas que precisam ser curadas. O objetivo desta abordagem é "reabilitar" as pessoas com deficiência (o que se saúda); porém, este entendimento incorpora uma visão de normalização, um velado preconceito de que algo está errado e que importa ser corrigido. Porque, dissimulada no estudo e na linguagem científica, existe latente uma alergia à diferença.

Sem, em momento algum, escamotear os benefícios da medicina, é premente reconhecer que este modelo centra-se na ideia de anormalidade ${ }^{12}$ e tem por génese uma perceção que coloca $o$ ónus na pessoa com deficiência, ou seja, é a pessoa com deficiência que precisa ser "modificada" para se adaptar ao ambiente e não o meio envolvente que deve ser modificado para comportar a pessoa com deficiência ${ }^{13}$.

O Modelo Social ${ }^{14}$, por seu turno, vê na deficiência o resultado do modo como a sociedade está organizada (ou desorganizada) e considera que essa (má) organização é que impõe à pessoa com deficiência as chamadas "barreiras", sendo que, de todas, a barreira comportamental é a mais intrincada, quiçá a mais difícil de ultrapassar, porquanto leva a pessoa com deficiência sentir-se desenquadrada, inibida e limitada.

De acordo com este modelo, contrariamente aos Modelos Médico e Caritativo, não cabe apenas ao indivíduo com deficiência superar os obstáculos, mas, também, compete à sociedade, em conjunto com a pessoa com deficiência, promover uma mudança de paradigma, de modo a remover as "barreiras". Ou seja, existe um ónus que recai sobre a sociedade, porquanto, quando uma pessoa com deficiência não pode fazer uma qualquer tarefa no seu quotidiano, seja porque não há elevadores, rampas, transportes públicos ou mobiliário adequado às suas necessidades específicas, tal significa que também a sociedade possui uma "deficiência".

Finalmente, começa a ser trilhado um Modelo baseado em Direitos, que é um complemento do modelo social, e talvez deva ser visto como o modelo ideal, uma vez que nele estão assegurados os direitos humanos básicos de qualquer pessoa, como o direito à vida, à saúde, à educação, ao trabalho ou à cultura.

A consagração deste modelo permite às pessoas com deficiência o direito a oportunidades iguais e à participação na sociedade, dando um forte contributo para a inclusão e a participação ativa e autónoma das pessoas com deficiência. É um modelo que rompe com os preconceitos e a

\footnotetext{
${ }^{11} \mathrm{O}$ Modelo Médico ganhou mais força após as duas grandes guerras com a criação de muitas Instituições Assistenciais nos moldes da AACD e APAE. Para esse Modelo, as pessoas com deficiência devem ser assistidas por profissionais e as mais "aptas" terão condições para se integrar na sociedade.

${ }^{12}$ Assim, FONTES, Fernando - Pessoas com Deficiência em Portugal. Lisboa: FFMS, 2016, p. 34.

13 Decorrente da aplicação do modelo médico, reclamam-se instituições especiais, hospitais com determinadas características, escolas especiais e empregos protegidos, e cuidadores que, na sua maioria, decidem o que fazer com estas pessoas.

${ }^{14} \mathrm{O}$ modelo social surge na sequência da luta pelos direitos das pessoas com deficiência iniciada pelos Movimentos de Pessoas com Deficiência (MPD), principais responsáveis por esta nova abordagem da deficiência, posteriormente designada por modelo social da deficiência (Oliver, 1990). O modelo social vem afirmar a deficiência como exterior ao indivíduo, algo socialmente constituído, que oprime e exclui as pessoas com deficiência. Visão oposta ao modelo médico que situa a deficiência no indivíduo. Tal como definida pelo Union of Phisical Impaired Against Segregation (UPIAS) em Inglaterra em 1976, a deficiência deve ser entendida como a desvantagem ou a restrição de atividade criada pelas instituições sociais, cuja não consideração das necessidades das pessoas com incapacidade impede a sua participação na sociedade e nas atividades sociais habituais para qualquer outro cidadão em geral (UPIAS, 1976).
} 
discriminação que ainda vislumbramos na sociedade e oferece às pessoas com deficiência oportunidades iguais para participar no devir da sociedade, enfatizando criticamente que as pessoas com deficiência ainda são privadas do exercício dos mais básicos e elementares direitos.

A defesa de um modelo baseado em Direitos é uma copérnica mudança de paradigma, a substituição de visão caritativa por um modelo assente nos Direitos Humanos, que todos podem e devem reivindicar. Corolário desta visão, convocam-se dois conceitos fundamentais: o empowerment (capacitação, fortalecimento dos meios de ação) e a responsabilidade (prestação de contas), sendo que o empowerment diz respeito à participação de pessoas com deficiência como partes interessadas ativas na defesa dos seus direitos, e a responsabilidade concerne ao dever das instituições públicas em implementar esses direitos.

A fundamental diferença entre um modelo social e um modelo assente em direitos é a de que este último acentua que compete à sociedade garantir e assegurar o pleno exercício e gozo dos direitos das pessoas com deficiência, que é obrigação da sociedade derrubar as várias barreiras que impedem estas pessoas de participar ativamente na tomada de decisões, bem como, convocar as pessoas com deficiência para exigirem o pleno exercício dos seus direitos cívicos, políticos e associativos. Será com base nestas premissas que se convidam as políticas públicas e a legislação a contribuir para derrubar as barreiras criadas pela sociedade. Sendo axiomático que esta não é uma competência exclusiva das instituições públicas, porquanto todos os cidadãos, principalmente as pessoas com deficiência ou os movimentos de pessoas com deficiência (MPD), devem pugnar para implementar estas medidas e fiscalizar o seu cumprimento efetivo, não ignoramos a função pedagógica do Estado e o jus imperii de que é proprietário exclusivo, pelo que, exige-se dos poderes públicos um comportamento ativo, mormente ao nível legiferante.

\section{A TIPOLOGIA DOS DIREITOS DAS PESSOAS COM DEFICIÊNCIA}

$A b$ initio um prelúdio: se consagrar direitos é crucial, ainda mas importante é operacionalizá-los. Infelizmente, o caleidoscópio dos direitos das pessoas com deficiência assemelha-se a uma pintura barroca, um intrincado jogo de luzes e sombras, amiúde retorcido, em que os direitos escondem-se nas normas, obrigando o intérprete a garimpar perante uma pletora de normas, para conseguir decifrar quais (e como se operam) os direitos de que se podem socorrer. $\mathrm{O}$ que ora tentamos realizar.

No topo da pirâmide, trazemos à colação a Convenção das Nações Unidas sobre os Direitos das Pessoas com Deficiência, que

relembrando os princípios proclamados na Carta das Nações Unidas, reconhece a dignidade e o valor inerente a todos os membros da família humana e os seus direitos iguais e inalienáveis como base para a fundação da liberdade, justiça e paz no mundo.

É insofismável que a Convenção dos Direitos das Pessoas com Deficiência constitui um marco histórico na garantia e promoção dos direitos humanos de todos os cidadãos e em particular das Pessoas com Deficiência, vinculando os Estados que a ratificaram a um conjunto de 
obrigações ${ }^{15}$. E, sem hipocrisias nem irrealismos, se muitas das medidas prescritas têm custos e os (alguns) Estados não têm condições para os implementar imediatamente, é a própria Convenção que apela à "realização progressiva" da maior parte das suas disposições, em função dos recursos de cada país.

Quando convocamos o Direito interno, surge a Constituição da República Portuguesa como a cidadela de proteção dos direitos, porquanto a incorporação destes na Constituição os torna vinculativos para as entidades públicas e privadas.

Sucede que, a Constituição da República Portuguesa é displicente na proteção jurídica da pessoa com deficiência, esgotando a problemática num único artigo. A frase, jogada assim no texto, tem uma carga demagógica que não ignoramos. Como, é suscetível de ser classificada de anacrónica, escamoteando que a forma como a lei e a sociedade interpretam a problemática da deficiência sofreu uma alteração copérnica, sendo a norma constitucional o produto de um determinado momento histórico. Mas se tudo isto é verdade, tudo isto é triste, não tem de ser um fado: porque, se é certo que a constituição foi elaborada em 1976, a norma constitucional posta é o produto das revisões de 1982, 1989, 1992, 1997, 2001, 2004 e 2005, sendo inadmissível que nas sete revisões estas temáticas tenham sido sumptuosamente ignoradas por um legislador constituinte, sempre sôfrego com a espuma dos dias, mas insensível no que concerne à tutela constitucional dos mais frágeis entre os mais frágeis, reiteradamente esquecendo a centralidade que hoje se reconhece à Pessoa humana, à sua dignidade e liberdade ${ }^{16}$.

No entanto, importa trazer para este texto um truísmo: a pessoa com deficiência é uma pessoa e, enquanto tal, mantém intactos todos os seus direitos fundamentais. Sublinhar este ponto parece um dislate, mas a realidade do quotidiano (ainda) nos demonstra que este aspeto é demasiadas vezes esquecido e, em determinadas situações os desejos e interesses da pessoa com deficiência são sumptuosamente ignorados, sendo esta infantilizada, amiúde coisificada, expropriada da sua autonomia, e, muitas vezes, decisões que são suas, e apenas Suas, são transferidas para os seus cuidadores, numa inaceitável violação dos direitos fundamentais. Ciente deste atropelo, e de forma a proteger e respeitar a autonomia e autodeterminação das pessoas com deficiência, a Convenção dos Direitos das Pessoas com Deficiência determina, no seu artigo 19. ,

\footnotetext{
${ }^{15}$ Nomeadamente, (i) velar por que seja reconhecida a igualdade perante a lei, incluindo o direito a possuir e herdar bens, a controlar os seus assuntos financeiros e a ter acesso a empréstimos, crédito e hipotecas; (ii) introduzir leis e medidas administrativas que garantam a proteção contra a exploração, a violência e os maus tratos; (iii) favorecer a recuperação e a reabilitação da pessoa vítima de maus tratos e apresentar o culpado à justiça; (iv) promover a mobilidade pessoal, facilitando o acesso a dispositivos de apoio à mobilidade; (v) assegurar, na medida do possível, a adaptação dos espaços físicos, como escolas e locais de trabalho, isto é, efetuar as alterações e ajustamentos que permitam a inclusão das pessoas com deficiência; (vi) assegurar o respeito pelo direito das pessoas com deficiência a terem uma vida autónoma e não ser obrigadas a residir em locais específicos; (vii) assegurar o seu direito a casar e a constituir família; (viii) integrar os alunos com deficiência no sistema educativo geral, prestando-lhes o apoio necessário, quando for preciso; (ix) assegurar a igualdade de acesso à formação profissional, à educação para adultos e à educação permanente; (x) prestar os cuidados de saúde e os serviços médicos específicos necessários devido às deficiências; (xi) proteger o direito ao trabalho e proibir a discriminação no emprego; (xii) promover o emprego, o trabalho independente e o empreendedorismo das pessoas com deficiência; (xiii) assegurar um nível de vida e uma proteção social adequados, incluindo a habitação social, uma assistência que responda às necessidades ligadas à deficiência e ajuda financeira, se a pessoa, além de possuir uma deficiência, tiver insuficiência económica; (xiv) garantir a participação na vida pública e política, na vida cultural, nos lazeres, nas distrações e no desporto.

16 Semelhantemente, ALVES, Raúl Guichard - Alguns Aspectos do Instituto da Interdição. In: Interdição e Inabilitação. [Em linha]. Lisboa: CEJ. [Consult. 01 dez. 2017]; Disponível em: www.cej.mj.pt/cej/recursos/ebooks/civil/Interdicao_inabilitacao.pdf, p. 40.
} 
que Os Estados Partes na presente Convenção reconhecem o igual direito de direitos de todas as pessoas com deficiência a viverem na comunidade, com escolhas iguais às demais e tomam medidas eficazes e apropriadas para facilitar o pleno gozo, por parte das pessoas com deficiência, do seu direito e a sua total inclusão e participação na comunidade. Neste sentido, foi criado pelo Governo português e instituído pelo Decreto-lei nº129/2017, de 9 de outubro, através do MAVI (Modelo de Apoio à Vida Independente), que consiste na disponibilização de um serviço de assistência pessoal de apoio à pessoa com deficiência ou incapacidade, para a realização de atividades que, em razão das limitações decorrentes da sua interação com as condições do meio, esta não possa realizar por si própria. ${ }^{17}$

Concomitantemente, a Lei n. ${ }^{\circ} 46 / 2006$, de 28 de agosto, vem reforçar o texto constitucional (ainda que no art. 13. ${ }^{\circ}$ exista uma inconcebível omissão sobre a proibição de discriminação em razão de deficiência), com o desiderato de prevenir e proibir a discriminação, directa ou indirecta, em razão da deficiência, sob todas as suas formas, e sancionar a prática de actos que se traduzam na violação de quaisquer direitos fundamentais, ou na recusa ou condicionamento do exercício de quaisquer direitos económicos, sociais, culturais ou outros, por quaisquer pessoas, em razão de uma qualquer deficiência.

Com efeito, quando baixamos para o patamar infraconstitucional, destaca-se a Lei $\mathrm{n}^{\circ}$ 38/2004, de 18 de agosto, que define as bases gerais do regime jurídico da prevenção, habilitação, reabilitação e participação da pessoa com deficiência. A ratio legis da norma é apelar à participação das pessoas com deficiência na sociedade, através da promoção da igualdade de oportunidades numa perspetiva holística, nomeadamente no que respeita ao acesso à educação, à formação, ao emprego/trabalho, à aprendizagem ao longo da vida, aos serviços de apoio e ao direito ao lazer e à cultura. A Lei apela, ainda, à promoção de uma sociedade inclusiva, através da eliminação de barreiras arquitetónicas e comunicacionais e prescreve a adoção de medidas que visem a plena participação da pessoa com deficiência.

Não obstante as boas intenções, que se saúdam e aplaudem, a norma é prolixa na consagração dos diversos direitos específicos das pessoas com deficiência, sendo que o regime jurídico aplicável às pessoas com deficiência é uma complexa manta de retalhos, expresso através de um emaranhado de normas, intrincadas de decifrar. Dessarte, a principal dificuldade das pessoas com deficiência é conhecer os seus direitos, que tendem a perder-se em diversos diplomas avulsos, enredando estas pessoas em meandros que desconhecem. Dessarte, nem todas as pessoas têm o conhecimento necessário para aceder às normas, realizar com sucesso a sua hermenêutica, de molde a poderem usufruir dos seus legítimos direitos. Até porque, reiteradamente, o legislador parece ignorar que o seu destinatário não é a tribo dos juristas eruditos, mas o cidadão comum, despido de conhecimentos técnicos. E se a ignorantia juris non excusat, amiúde ficamos com a desagradável sensação que a complexidade jurídica é premeditada para afastar o cidadão da jurisdicidade.

Por tudo, e cientes dos riscos [nomeadamente que este poderá ser mais um fator de discriminação], defendemos, de lege ferenda, a instituição de um Estatuto da Pessoa com Deficiência que reúna o acervo jurídico aplicáveis nestas circunstâncias.

Porque tal inexiste, o primeiro [e único] objetivo deste texto é trilhar o caleidoscópio dos direitos das pessoas com deficiência, oferecendo uma ontologia dos seus direitos, desconstruindo

\footnotetext{
${ }^{17}$ Este Programa irá realizar-se através de um Projeto-piloto em Portugal com duração de 3 anos e tem início no princípio do ano de 2019.
} 
conceitos [criticando outros!], traduzindo a arreigada construção jurídica por conceitos apreensíveis pelo cidadão comum. Dito com outra roupagem, ajudar a permitir que o cidadão com deficiência (re)conheça os direitos consagrados na norma posta.

Começamos a nossa viagem pelo direito à saúde (sem que começar a peregrinação pelos direito específicos das pessoas com deficiência pelo direito à saúde não é repristinar o modelo médico nem aderir a este, apenas significa ignorar que existe uma dimensão médica, que as deficiências e incapacidades são patologias que exigem o saber da medicina), para enfatizar que, para a pessoa com deficiência usufruir de todos os seus direitos legalmente previstos, necessita obter, primeiramente, um comprovativo da sua incapacidade, o atestado médico de incapacidades multiusos $^{18}$, que atesta o seu grau de incapacidade, e é prova essencial para múltiplas finalidades.

Este atestado dá direito, inter alia, à isenção de taxas moderadoras (conforme o disposto no Decreto-Lei n. ${ }^{\circ}$ 113/2011, de 29 de novembro), beneficiar de assistência de cuidados médicos e de enfermagem no domicílio, mediante prescrição médica, usufruir de uma Rede Nacional de Cuidados Continuados Integrados (RNCC), assegura os encargos com o transporte não urgente para tratamentos e consultas, e ainda, pode permitir a aquisição de produtos de apoio ${ }^{19}$, uma das maios prementes dificuldades das pessoas com deficiência (e das famílias) devido aos seus elevados custos.

Porque há uma ligação quase umbilical entre a deficiência e a pobreza, uma triste profecia autofágica que se autoconcretiza, porquanto as pessoas com deficiência são discriminadas no ensino, afastados do mercado de trabalho, condenando-as a viverem com míseros rendimentos, promovendo-se a pobreza, releva a importância das pensões e subsídios. Efetivamente, se há categoria de pessoas em que faz sentido o apoio económico do Estado é, indubitavelmente, a das pessoas com deficiência [até porque, outra seria a realidade, se o quotidiano da deficiência fosse a vida de Philippe, personagem principal do magnífico filme Amigos Improváveis].

Para atenuar o problema [sendo uma diminuta atenuação, muito aquém das mais básicas necessidades], existe um conjunto de pensões e subsídios aos quais as pessoas com deficiência podem recorrer, nomeadamente, a bonificação do abono de família para crianças e jovens com deficiência, a prestação social para a inclusão, o subsídio de educação especial, o subsídio para assistência a fillho com deficiência ou doença crónica, a pensão de invalidez, e o subsídio por assistência de $3^{a}$ pessoa.

Por razões evidentes, a Autoridade Tributária e Aduaneira (AT) prevê tratamento fiscal diferenciado para os contribuintes com deficiência fiscalmente relevante, ou seja, que apresentem um grau de incapacidade, permanente e devidamente comprovada, igual ou superior a $60 \%$, de acordo com o n. ${ }^{\circ} 5$ do artigo $87^{\circ}$, do Código do IRS. Dessarte, existem benefícios fiscais por incapacidade em sede de Imposto sobre Rendimentos de Pessoas Singulares (IRS), isenção de

\footnotetext{
${ }^{18}$ Previsto no Decreto-Lei n. ${ }^{\circ}$ 202/96, de 23 de outubro, com alterações introduzidas pelo Decreto-Lei n. ${ }^{\circ} 291 / 2009$, de 12 de outubro. Assim, os cidadãos com deficiência, a que corresponda um grau de incapacidade igual ou superior a $60 \%$, calculada de acordo com a Tabela Nacional de Incapacidades, podem ter acesso às medidas e benefícios previstos na lei, ainda que estes possam estar condicionados em função do grau de incapacidade, o fim a que se destina ou outras especificidades

${ }^{19}$ Define-se produto de apoio como "qualquer produto (incluindo dispositivos, equipamentos, instrumentos, tecnologia e software), especialmente produzido ou geralmente disponível, para prevenir, compensar, monitorizar, aliviar ou neutralizar as incapacidades, limitações das atividades e restrições na participação” (Norma ISO 9999:2007).
} 
Imposto sobre o Valor Acrescentado (IVA), Imposto Único de Circulação (IUC), Imposto sobre veículos.

Num segundo patamar de direitos, encontramos, entre outros, o direito ao ensino. De crucial importância, não fosse o acesso à educação um dos mais importantes pilares da sociedade. Mais. O exercício de muitos dos direitos civis e políticos, tais como a liberdade de informação, liberdade de expressão, direito ao voto e a ser eleito, entre outros, para ser efetivo, exige um nível mínimo de educação. Acresce que, o combate à discriminação também se constrói pela educação, sendo a iliteracia uma das mais torpes formas de discriminar. Assim, compete ao Estado assegurar que as crianças com deficiência tenham acesso a um ensino, primário e secundário, inclusivo, de qualidade e gratuito, em isonomia com as demais pessoas nas comunidades em que vivem ${ }^{20}$. Para tanto, o Estado tem a obrigação de providenciar adaptações razoáveis em função das necessidades individuais, bem como, fornecer medidas de apoio individualizadas eficazes em ambientes que maximizem o desenvolvimento académico e social, consistentes com o objetivo de plena inclusão. Acresce a existência de um subsídio por frequência de estabelecimento de educação especial, atribuído às pessoas com deficiência, com menos de 24 anos, que frequentem um estabelecimento de educação especial tutelado pelo Ministério da Educação ou um estabelecimento particular de ensino regular que implique o pagamento de uma mensalidade e de bolsa de estudo para alunos a frequentar o ensino superior.

Quando abandonamos um modelo caritativo e interpretamos a pessoa com deficiência como uma pessoa no pleno gozo dos seus direitos, quando pugnamos pela sua autonomia e defendemos a sua autodeterminação, importa garantir o seu direito à habitação. Sucede que, tradicionalmente, as pessoas com deficiência foram encontrando obstáculos quase intransponíveis no acesso ao crédito à habitação, nomeadamente a exigência, pelas instituições de crédito, de um seguro de vida, reiteradamente negado pelas seguradoras, num execrável ato de discriminação no direito de acesso à habitação. Ciente dessa realidade e após anos de protestos, o legislador, através da Lei n. ${ }^{\circ}$ 64/2014, de 26 de agosto, veio pôr fim à exigência do seguro de vida para os empréstimos solicitados por pessoas com deficiência, bem como permitir a estas pessoas o acesso ao crédito bonificado. Refira-se ainda a existência de apoios ao arrendamento, previstos no Decreto-Lei $\mathrm{n}^{\circ}$ 156/2015, de 10 de agosto, que visa proteger inquilinos economicamente desfavorecidos, mormente, pessoas com deficiência com grau comprovado de invalidez igual ou superior a $60 \%$, cujas rendas sofreram um aumento com a aplicação do NRAU. Por fim, as pessoas com deficiência podem, também, candidatar-se à habitação social, e ao Mercado Social de Arrendamento.

Um dos mais importantes direitos que os cidadãos com deficiência reclamam é o direito ao emprego. Por razões axiomáticas e axiológicas. Dessarte, é através do salário [quando digno!] que a pessoa com deficiência consegue contrariar a pobreza e a exclusão social; como, estar inserida no mercado de trabalho é crucial para potenciar a sua autoimagem e autoestima. Porque Arthur Schopenhauer tem razão e se a honra é, objetivamente, a opinião dos outros acerca do nosso valor, esta, subjetivamente, é o nosso medo dessa opinião: e ninguém acredite que toda uma narrativa implícita de preconceitos sobre a pessoa com deficiência não afeta e melindra aqueles que se encontram nesta situação. Ciente desta verdade, o Decreto-Lei n. ${ }^{o}$ 290/2009, de 12 de outubro, instituiu o Programa de Emprego e Apoio à Qualificação das Pessoas com Deficiência e Incapacidade e definiu o regime de concessão de apoio técnico e financeiro para o desenvolvimento das políticas de emprego e apoio à qualificação daquelas.

\footnotetext{
${ }^{20}$ Conforme, o Decreto-Lei n. ${ }^{\circ}$ 54/2018 de 6 de julho.
} 
Também o acesso à cultura, ao lazer e ao desporto são uma parte fundamental da vida em sociedade que não podem ser sonegados às pessoas com deficiência, porquanto representam um importante fator no combate ao isolamento social. Dessarte, estas áreas devem estar acessíveis a todos de um modo inclusivo, criando assim isonomia e igualdade de oportunidades. Para tanto, é conditio sine qua non adaptar os locais onde decorrem os eventos de forma a eliminar as barreiras físicas e comunicacionais e estimular a participação das pessoas com deficiência nestes eventos.

Merece ainda referência a existência de um Cartão de Estacionamento para pessoas com deficiência $^{21}$ e o atendimento prioritário às pessoas com deficiência ${ }^{22}$, que têm uma dimensão prática que nem sempre os teóricos compreendem.

\section{CONCLUSÃO}

Este estudo não esgota os direitos que a lei reconhece à pessoa com deficiência. Desde logo, porque esta, enquanto cidadã, goza dos mesmos direitos e deveres que qualquer outro cidadão, premissa que está abscôndita em cada uma das nossas reflexões.

O que procurámos fazer foi combater o obscurantismo que continua a afastar as pessoas com deficiência da plena cidadania e pelejar contra a invisibilidade em que permaneceram por demasiados anos. Para tanto, construímos um catálogo predominantemente panorâmico com alguns dos mais pertinentes direitos, uma espécie de guia que, antes de qualquer outra motivação, permita dar a conhecer os direitos que existem e as formas de os operacionalizar. Sem eruditismos nem especiais preocupações dogmáticas e doutrinais. Quiçá demasiado descritivo, porque a intenção assumida, deste o parágrafo inicial, foi trazer luz a uma escuridão que priva a pessoa com deficiência do conhecimento dos seus direitos. Dessarte, se os direitos existem, constatamos que há uma nuvem de opacidade que afasta a pessoa com deficiência do seu exercício. Nesse sentido e cientes dos riscos, somos favoráveis à estatuição de um Estatuto da Pessoa com Deficiência que reúna num único diploma todos os direitos específicos deste grupo social. E, escrevemos com a desagradável sensação de que a pletora de normas perdidas em legislação extravagante esconde o desejo de encobrir estes direitos e impedir o seu pleno exercício. Por um intolerável e insensível economicismo, uma espécie de avareza (social, política, económica e cultural).

Mediatamente, também pretendemos desocultar esta realidade, procurando implodir preconceitos, mitos e lugares-comuns, reafirmando a dignidade das pessoas com deficiência. Cientes de que as mentalidades não se mudam por decreto-lei nem que bastam algumas palavras bem-intencionadas, aqui e em outros (con)textos, calar-nos não é uma opção. Porque se tinha uma pedra no meio do caminho, se no meio do caminho tinha uma pedra a questão não é nunca esquecer esse acontecimento na vida de minhas retinas tão fatigadas como prescreveu Carlos Drummond de ANDRADE, mas evocar Fernando PESSOA, guardar todas as pedras e um dia construir um castelo.

Este é o nosso modesto contributo para estes alicerces.

\footnotetext{
${ }^{21} \mathrm{O}$ atual cartão de estacionamento de modelo comunitário para pessoas com deficiência condicionadas na sua mobilidade foi aprovado pelo Decreto-Lei n. ${ }^{\circ}$ 307/2003, de 10 de dezembro, posteriormente alterado pelo Decreto-Lei n. $^{\circ}$ 17/2011, de 27 de janeiro, e pela Lei n. ${ }^{\circ}$ 48/2017, de 7 de julho, alterado pelo Decreto-Lei n. ${ }^{\circ} 128 / 2017$ de 9 de outubro

${ }^{22}$ Decreto-Lei n ${ }^{\circ}$ 135/99, de 22 de abril, alterado e republicado pelo Decreto-Lei n. ${ }^{\text { }}$ 73/2014, de 13 de maio, com a alteração introduzida pelo Decreto-Lei n. ${ }^{\circ}$ 58/2016, de 29 de agosto.
} 


\section{REFERENCIAS:}

ALVES, Raúl Guichard - Alguns Aspectos do Instituto da Interdição. In: Interdição e Inabilitação. [Em linha]. Lisboa: CEJ. [Consult. 01 dez. 2017]; Disponível em: www.cej.mj.pt/cej/recursos/ebooks/civil/Interdicao_inabilitacao.pdf;

ARAUJO, Luiz David - A Proteção Constitucional das Pessoas Portadoras de Deficiência. Brasília: Coordenadoria Nacional para a Integração da Pessoa Portadora de Deficiência, 1997;

DHANDA, Amita - Construindo um Novo Léxico dos Direitos Humanos: convenção sobre os direitos das pessoas com deficiência. "Revista Internacional de Direitos Humanos". São Paulo, a.5, n.8, pp. 42-59;

FERNANDES, Ana Paula e DENARI, Fátima - Pessoa com Deficiência: estigma e identidade. "Revista FAEEBA". Salvador, v. 26, n. 50, pp. 77-89;

FONTES, Fernando - Pessoas com Deficiência em Portugal. Lisboa: FFMS, 2016.

LIMA, Andrei e DORNELLES, Daniélle - Dignidade-Vulnerabilidade Versus DignidadeLiberdade - um estudo crítico do estatuto da pessoa com deficiência a partir do conceito de dignidade da pessoa humana. [Em linha]. Lima: Facultad de Derecho de la Pontificia Universidad Católica del Perú. [Consult. 01 set. 2017]; Disponível em: http://themis.pe;

MAIA, Ana Bortolozzi e RIBEIRO, Paulo Marçal - Defazendo Mitos para Minimizar o Preconceito sobre a Sexualidade de Pessoas com Deficiência. Revista Brasileira de Educação Especial. Marília. V. 16, n. 2, oo. 159-176.

MANNOCCI, Fernanda - Educação em Sexualidade e a Pessoa com Deficiência Intelectual. "Revista Educação". São Paulo. V. 12, n. 1, pp. 80-101;

MARCÍLIO, Lucas - Estatuto da Pessoa com Deficiência e Reflexos na Incapacidade Civil: avanços e retrocessos. [Em linha]. ETIC, v. 13, n13. [Consult. 01 set. 2017]; Disponível em: www.intertemas.toledoprudente.edu.br/revista/índex;

MARTINS, Ana Camilo - Cidadanias Esquecidas: o caso de pessoas com deficiência. [Em linha]. Universidade da Beira Interior: Covilhã. [Consult. 01 set. 2017]; Disponível em: https://ubibliorum.ubi.pt/handle/10400.6/2431;

NASPOLINI, Ludmila - A Proteção aos Direitos da Pessoa com Deficiência. "Revista do CEJUR/TJSC". Rio Grande do Sul. v. V, n. 1, pp. 229-251;

NEVES, Alexandra - O Estatuto dos "Cidadãos Invisíveis": o longo caminho para a plena cidadania das pessoas com deficiência. [Em linha]. Lisboa: Universidade Autónoma de Lisboa. [Consult. 01 jul. 2017]; Disponível em: http://repositorio.ual.pt; 
PIMENTEL, Susana e PIMENTEL, Mariana - Acessibilidades para a Inclusão da Pessoa com Deficiência: sobre o que estamos falando. "Revista FAEEBA". Salvador, v. 26, n. 50, pp. 91103;- RIBEIRO, Simone - Lei 13.146/2015 - Estatuto da Pessoa com Deficiência e suas Consequências: da incapacidade civil e interdição. [Em linha]. Porto Alegre: Universidade Federal do Rio Grande do Sul. [Consult. 01 set. 2017]; Disponível em: www.lume.ufrgs.br;

PINHEIRO, Jorge Duarte - As Pessoas com Deficiência como Sujeitos de Direitos e Deveres: incapacidades e suprimentos - a visão do Jurista. [Em linha]. Lisboa. [Consult. 01 set. 2017]; Disponível em: https://www.icjp.pt/sites/default/files/media/600-886.pdf:

RODRIGUES, Camila - A Pessoa com Deficiência Física: conceitos históricos e epistemológicos.

SAMPAIO, Maria Carvalho - Regime Jurídico das Incapacidades: novo instituto para a protecção dos idosos. [Em linha]. Revista Julgar. [Consult. 01 set. 2017]; Disponível em: http://julgar.pt/wp-content/uploads/2016/12/20161209-ARTIGO-JULGAR-RegimeJur\%C3\%ADdico-das-Incapacidades-Novo-Regime-para-a-Prote\%C3\%A7\%C3\%A3o-dosIdosos-Concei\%C3\%A7\%C3\%A3o-Sampaio.pdf;

SANTOS, Ana Silva - Inserção Socioprofissional e Empregabilidade da pessoa com deficiência: contributos das ofertas de formação. [Em linha]. Coimbra: Universidade de Coimbra. [Consult. 01 set. 2017]; Disponível em: https://estudogeral.sib.uc.pt;

SHIGEMATSU, Letícia - A Nova Perspectiva do Estatuto da Pessoa com Deficiência e seus Reflexos no Sistema de Incapacidades do Código Civil. [Em linha]. São Paulo: Centro Universitário António Eufrásio de Toledo. [Consult. 01 set. 2017]; Disponível em: http://intertemas.unitoledo.br;

SILVA, Aurya - Novo Estatuto da Pessoa com Deficiência, e Suas Implicações a Curatela. [Em linha]. CARUARU: Centro Universitário Tabosa de Almeida. [Consult. 01 set. 2017]; Disponível em: http://repositorio.asces.edu.br/handle/123456789/832;

SIMÕES, Cristina - O Direito à Autodeterminação das Pessoas com Deficiência. Porto: APPCFDUP, 2016.

SOUSA, António Pais - Da Incapacidade Jurídica dos Menores, Interditos e Inabilitados no Âmbito do Código Civil. Coimbra: Livraria Almedina, 1971.

STEFFEN, Luciana - Direitos Sexuais e Direitos Reprodutivos das Mulheres com Deficiência e o Blog "Sobre Rodas". "Anais do Congresso Latino-Americano de Gênero e Religião". São Leopoldo. V.5, pp. 401-407;

SOALHEIRO, Luiza e CANÇADO, Paula - A Garota Dinamarquesa: reflexão sobre o direito fundamental à sexualidade. "Revista de Género, Sexualidade e Direito”. Brasília, v. 3, n.1, pp. 116 ; 
TRABUCO, Cláudia - O Regime das Incapacidades e Respectivo Suprimento: perspectivas de reforma. [Em linha]. Lisboa: FDUNL. [Consult. 01 set. 2017]; Disponível em:

www.fd.unl.pt/docentes_docs/ma/ct_MA_5013.doc 